A framework for the study of written and spoken discourse: School mathematics in Palestine

Jehad Alshwaikh and Candia Morgan

Jehad Alshwaikh

Associate Professor

Curriculum and Instruction Department, Faculty of Education

Birzeit University

Palestine

jalshwaikh@gmail.com

Candia Morgan

Professor of Mathematics Education

Department of Curriculum Pedagogy and Assessment

University College London Institute of Education

UK 


\title{
A framework for the study of written and spoken discourse: School mathematics in Palestine
}

\author{
Jehad Alshwaikh and Candia Morgan
}

\begin{abstract}
The way in which mathematics is communicated and represented in schools (including the written language, symbols and diagrams of mathematics textbooks and the verbal/spoken classroom interaction itself) constructs particular views of the nature of mathematics and expectations about students' participation in mathematical activity. In a previous article, we developed an analytic framework for examining the nature of mathematics and mathematical activity in textbooks in Palestinian schools and England. Here we extend our analysis to include the verbal/spoken language in two classrooms. To illustrate the application of the suggested framework, we present three cases from a particular social context (Palestine). We analyse an instance of a written textbook for grade 7 and spoken discourse in two classes in grades five and six. We show how studying written and spoken discourse enables us to draw a picture of mathematics, mathematical activities and learning mathematics in schools context.
\end{abstract}

School mathematics; written and spoken discourse analysis; nature of mathematics; learner activity; social semiotics

\section{A discursive perspective on school mathematics}

It is widely recognised that the objects of mathematics are discursive to the extent that they are only available to us through 'representations' in language, specialised notations, diagrammatic, graphical or other modes of communication (Duval, 2006) or, to take a more extreme ontological position, they are brought into existence through the use of such communicational means (Sfard, 2008). The activity of doing mathematics, whether in school, academia or other settings, is thus highly discursively saturated (Dowling, 1998); its principles can be described discursively. Indeed, Sfard (2012) argues that mathematics can be seen as an activity of telling stories about the world in which the characters are mathematical objects. School mathematics can be perceived as an apprenticeship into participation in forms of discourse that are valued as mathematical: using the specialised language and other communicational modes, engaging in specialised routines or discursive patterns and coming to recognise the kinds of narratives about the world that may be endorsed as mathematical (Sfard, 2008). Of course, what is valued and endorsed as mathematical varies from one context to another, as is evident when we consider the variation in teaching and learning seen in mathematics classrooms around the world. While the mathematical topics included in the curriculum may be broadly similar across many jurisdictions, the ways in which students are expected to engage with the mathematics, the ways they are expected to behave and their relationships with the subject matter, with their teacher and other students vary.

Understanding school mathematics must thus involve studying not only the mathematical content but also the behaviours and interactions of teachers and students. From a discursive 
perspective, this entails studying the wide range of texts that form part of school mathematics activity, including written texts such as textbooks, student notebooks, examination papers but also spoken texts produced in classroom interactions. Our aim in this article is to start to develop and illustrate the use of an analytic scheme that can be applied to this wide variety of texts in order to characterise important aspects of school mathematics.

In this article, there are three main notions we use in a specific way: discourse, text and activity. We look at discourse with a Foucauldian lens, as expressed in the work of Social Semiotics and the Critical Discourse Analysis, to mean the socially produced knowledge and values that are shared among specific group of people (Kress, 2011). In that sense, text means an instance or a specific event of that discourse mostly expressed in a scripted mode. Within the discourse of teaching and learning school mathematics, activity for us is the act of doing mathematics whether by teachers or students (c.f. Maheux \& Proulx, 2015 where authors argue that the act of doing is mathematics itself).

In recent years, the conceptualisation of mathematics in general and school mathematics in particular as social practices has become an important way of interpreting mathematical phenomena within their social contexts (see for example, Baker 1998; Lerman 2000; Morgan 1996; Sfard, 2008). Language, as a social phenomenon, plays a significant role in forming social practices and studying language itself may thus provide insight into the social practices of mathematics and mathematics education (Morgan, 2006). Such study requires systematic means of describing the language and interpreting its role in the practices of mathematics and school mathematics. The functional theory of language found in the social semiotic work of Halliday has been found useful in this respect and has been applied to mathematical discourse by a number of researchers including Pimm (1987), Morgan (1996) and O'Halloran (2005). From a slightly different starting point, Sfard (2008) has also developed important theoretical and methodological tools for the study of mathematical discourse.

Halliday's social semiotics argues that any text fulfils three metafunctions: ideational, interpersonal and textual - realised in the lexicogrammatical features of the text. The ideational metafunction refers to the representation of experience and ideas about the world this can be analysed using, for example, the transitivity system in language (the choices of actors, processes and circumstances and the relationships between these). The interpersonal metafunction focuses on identities and social relationships between the author and the reader: this can be analysed through the modality of the texts. The way in which texts are put together in a coherent way constitutes the textual metafunction - this metafunction can be analysed by looking at the thematic structure and cohesion of the text. See Morgan (2006) for a more detailed account.

While investigations of mathematical communication have focused mainly on written and spoken verbal language, other modes of communication such as algebraic notation, graphs, diagrams and gestures also play a role in doing, teaching and learning mathematics and have begun to be taken into account in mathematics education research (e.g. O'Halloran, 2005; Radford, 2009). This recognition of the multimodal nature of mathematical communication mirrors the theoretical and methodological development of social semiotic and functional approaches to the wider study of multimodal discourse (e.g. Jewitt, Bezemer \& O'Halloran, 2016; Kress \& Van Leeuwen, 2006). Our overall objective is to develop analytic tools that will enable us to investigate the full range of communication in mathematics classrooms. This entails considering the different modes of communication, including verbal language (both written and spoken), specialised mathematical notations, diagrams, graphs and other visual forms, and gesture. A closer look at the verbal communication in school contexts shows further complexity in language use, including use of distinct spoken and written forms 
of the same language, and various forms of multilingualism. In this article, we present some of the tools that we are developing to address this complexity and illustrate their application to a set of three multimodal texts sampled from the practice of teaching and learning mathematics in school. We set out to answer the following two broad questions:

1 What is mathematics and what kinds of activity are construed as mathematical in school mathematics?

2 What kinds of mathematical activity are school students expected to engage in?

Within this article we focus in particular on how mathematics is construed as a specialised domain and on whether the role of students is construed as thinking mathematically or following mathematical procedures and rules. In considering the role of students in mathematical activity, we adopt Rotman's (1988) distinction between scribbling (e.g. performing calculations or other manipulations) and thinking (mental activity such as imagining or reasoning). In the context of this article, we address the more specific questions:

1a. To what extent is specialised mathematical language used in school mathematics?

2a. What are learners expected to do and what possibilities are there for them to make decisions?

An important principle of social semiotics is that interpretation of the functioning of any text has to be informed by the context in which the text is produced and consumed. This includes both the immediate context of situation of the communication (including the established roles, relationships, practices and norms of the classroom) and the broader context of culture in which the school, the community and the participants are embedded. The example texts that we consider in this article are taken from school mathematics in Palestine. We thus need to understand something of the Palestinian mathematics education context in order to inform the analysis of these texts.

\section{The (Palestinian) context}

Mathematics in Palestinian schools, as in many other countries, is an obligatory subject from the first grade until grade 12, with broadly similar content and ordering of mathematical topics such as number, algebra and geometry. The low performance of Palestinian students in mathematics is of concern for mathematics educators and others whether at the national level (MoE, 2016) or in international tests such as TIMSS (Mullis, Martin, Foy, \& Arora, 2012). The concern extends to teachers' mathematical knowledge and teacher education programmes as researchers try to understand and explain students' performance.

Unfortunately, teachers, too, face challenges; the majority of the in-service teachers who participated in a study (Al-Ramahi, Alshwaikh \& Masad, 2016) were only able to identify the basic geometric shapes and reason informally about the relationships between these shapes, but were not competent in formal proof. The authors of the study also commented that school textbooks are densely packed with abstract concepts which makes mathematics a hard topic to learn and teach. Rewadi (2005) agreed with the critique of textbooks, suggesting that the nature of textbooks is linked to the modest achievement of Palestinian students in international and local studies.

The Palestinian educational system is centralised and controlled by the Palestinian Ministry of Education. All schools, including public, UNRWA (United Nations Relief and Works Agency for Palestine Refugees) and private, have to use the same textbooks produced by the Ministry of Education ${ }^{\mathrm{i}}$. The mode of teaching in Palestinian schools is mostly teachercentred. A typical description for a lesson would be that teachers start the lesson with a quick 
revision and reminder of the last lesson, lead the discussion using an IRF (initiationresponse-follow up) discourse pattern (Sinclair \& Coulthard, 1975) and assign tasks, assessment and homework. Alomar (2015) suggests that this practice corresponds to an instrumental approach, in spite of the fact that teachers tend to claim to support a problem solving view of mathematics. However, educational research in Palestine is dominated by a cognitive perspective and the notion of looking at mathematics and mathematics teaching and learning as social practice is still very young.

Beside the fact that we use the Palestinian context to illustrate the analysis we propose by the suggested framework, one can see the similarities between the Palestinian context and many other 'developing' contexts around the world such as the way in which mathematics is taught, the central role of teachers and the modest performance of students in mathematics nationally and internationally. For further details of the distinctive socio-political context in Palestine, see Alshwaikh \& Straehler-Pohl, 2017.

A further issue within the Palestinian context that will emerge during the discussion of our empirical studies later in this article is that of diglossia within the Arabic language. In modern Arabic there is a distinct difference between the written and spoken forms of the language that we consider to be significant for the teaching and learning of mathematics. There are two main types of Arabic: Classic or Standard Arabic (fus-ha فصحى) and Colloquial Arabic (ammiyya عامية). The former is the language of reading and writing (including both academic writing and more everyday texts such as newspapers). The latter is the spoken everyday language which people use to communicate in their daily life (with different forms of the colloquial Arabic in different Arab countries). This entails that children have to learn school subjects, including mathematics, in two different types of Arabic language. Maamouri (1998) discusses in detail some of the challenges that Arab children face when they start to be introduced to formal Arabic and the difference to their everyday language. For example, the fus-ha grammar that they are taught has little relation to the grammar of spoken Arabic. Hashem-Aramouni (2011) found that American students participating in Arabic programmes in higher education in the USA, aiming to become fluent in Arabic, experienced a discrepancy between the formal Arabic they learned in the course and the colloquial Arabic language they needed to communicate in the Arabic world. In spite of this, the dominant view within the Palestinian context is that diglossia is not a relevant issue in mathematics education because mathematics is a universal language. Given our orientation to mathematics teaching and learning as social practice taking place through multimodal communication, including both spoken and written Arabic, we reject this view and identify a need for research to consider the impact and implications of diglossia on learning and teaching mathematics in the Palestinian context. While diglossia is not the main focus of our study, it forms an important part of the communicative context and must be taken into account in analysing classroom discourse and in considering the implications for student learning.

\section{Methodology}

In order to illustrate how our approach allows us to address the research questions, we will present analyses of three cases from the social practice of mathematics education in Palestine. The first case focuses on written texts - the mathematics textbooks used in Palestinian schools. The data for this case arise from a collaborative project between the two authors, funded by the British Academy, where we looked at different topics in grades 4 through grade 10 (10 to 16 year old) textbook. The project developed an analytic framework for multimodal analysis of mathematics textbooks, whose details are published in Alshwaikh \& Morgan, 2013. The development of this framework drew on two main sources: the analytic framework developed by Morgan, Sfard and Tang (Tang, Morgan, \& Sfard, 2012; Morgan \& 
Sfard, 2016) to analyse examination questions and that developed by Alshwaikh (2011) for application to geometric diagrams. The framework is founded upon two theoretical perspectives. First, drawing on multimodal social semiotics (Halliday, 1985; Kress \& Van Leeuwen, 2006; Morgan, 2006), we contend that language, diagrams and other systems of communication function to construe the nature of our experience of the world and of the identities and relationships of participants. Second, we draw on Sfard's (2008) contention that thinking and doing mathematics can be considered as participating in mathematical discourse. The framework encompasses analytic categories and tools from the Hallaydian's Systemic Functional Language and multimodal social semiotics as well as from Sfard's characterisation of mathematical discourse. Morgan and Sfard (2016) present an argument for the compatibility of these theoretical perspectives.

The major components of the framework that we make use of in this paper relate to the ideational and interpersonal metafunctions of language, realising the field of discourse (in this case the nature of mathematical activity, including student engagement as agents in mathematical activity) and the tenor of discourse (in particular the ways in which students may be positioned in relation to mathematical activity). Each component is elaborated by questions that guide our analysis and indicators that allow us to identify relevant characteristics of the verbal and visual text.

In relation to the ideational metafunction, the properties of the discourse we considered were: specialisation, objectification, alienation, logical structure and status of mathematical knowledge. In the interpersonal metafunction, we considered activity, authority and formality. Given the space available here, we limit our discussion to the first property mentioned in each metafunction, namely specialisation as property of the discourse about the nature of mathematics, and positioning in relation to activity as property of the discourse about the students and their relationship to mathematics. Focusing on these two properties allows us to illustrate our methodological approach as well as identifying results that address our broad questions about the nature of school mathematics and expectations about students' mathematical activity.

Thus, in order to address our first question, What is mathematics and what kinds of activity are construed as mathematical in school mathematics?, we focused on the specialisation property of the discourse and address each text by asking "To what extent is specialised mathematical language used?". We did so by looking at indicators within the verbal and the visual texts. The indicators within the verbal text (written and spoken) were defined as: vocabulary used in accordance with mathematical definitions; 'conventional' expressions (e.g. corresponding angles زو ايا متناظرة); and specialised mathematical symbolic notation. When conducting the analysis of specialised vocabulary, we distinguish between mathematical objects (named by nouns or nominal groups) and processes (generally named by verbs). In considering specialisation in non-verbal text, indicators included: the use of conventional mathematical visual elements (e.g. geometric diagrams, charts, tables, graphs, etc.); conventional labelling systems (e.g. capital letters to indicate vertices etc.); 'conceptual' diagrams, showing properties and relationships, not actions). ${ }^{\text {ii }}$

To address the second question: What kinds of mathematical activity are students expected to engage with?, we focused on the positioning of learners in relation to activity in the discourse and address each text by asking "What is the learner expected to do?" and "What possibilities are there for learners to make decisions?". Again, we did so by looking at indicators within the verbal and the visual texts. Within the verbal text (the written and the spoken) we inspected the processes ascribed to the learner, categorising these as 'thinking' or 'scribbling' processes (Rotman, 1988). We also noted whether tasks were given by use of the imperative 
mood (indicating a lack of choice for the learner) or by posing questions (allowing some space for learners to decide how to address the task). The indicators within the visual text were the presence (or absence) of labelling such as naming vertices or marks indicating equal lengths and angle suggesting form of engagement with diagrams (learners as observers versus learners engaging in reasoning).

In this article, we make two assumptions. Firstly, we start from the assumption that the analytic framework, initially developed to look at communication in the English language, can be used to look at communication in Arabic. The first author has explored this issue and the challenges faced in adapting the framework to apply to Arabic text (Alshwaikh, 2016). Secondly, we assume that, originally developed to look at the written textbooks, the framework is also applicable to spoken texts, although it may not be comprehensive. We base this assumption on our understanding of all communication as multimodal; multiple semiotic modes occur together in meaning making (Jewitt, Bezemer \& O'Halloran, 2016; Kress \& Van Leeuwen, 2006). In other words, writing and speaking cannot be considered as completely distinct since they inevitably happen together in the school context (regardless of the differences between the modalities. Of course, in practice, the different resources employed in different modes introduce new semiotic possibilities that need to be incorporated into the analytic framework. While the framework provides tools for analysing the verbal component of face-to face communication, including reference to visual images and use of some types of gesture particularly relevant to school mathematics contexts (drawing on Alshwaikh, 2011), it would require further development to incorporate a wider set of gestures and other bodily activity such as gaze or posture. As new types of text are considered, the framework may also need to expand to encompass their characteristics and potential for meaning making. In particular, the potential offered by new technological forms of communication has not yet been built into the framework (cf. Morgan, Mariotti \& Maffei, 2009).

We thus apply the same framework to the analysis of the second and third cases, which focus on the spoken language of two classroom teachers and their use of multimodal resources. The texts we analyse are videos of teacher-student interaction from two lessons from two classrooms (grade 5 and grade 6) in a private Palestinian school which follows the usual Palestinian curriculum in grades 1-6. Each lesson lasted for 40 minutes and was video recorded by another researcher with coordination with the first author. Both lessons were taught in Arabic (Standard and Colloquial - see the discussion about diglossia). The video record focused on the teacher and no students were shown. There were 20 students on average in the two lessons. The two teachers were selected on the basis of their availability and their interest in participation. The first author transcribed most of the lessons in Arabic. In the case of textbook, the verbal transcript followed the analytic tool structure and consisted of four columns to answer each research question, the first column was for the property of the discourse (e.g. specialisation) and leading question for the analysis was "To what extent is specialised mathematical language used?". The third and the fourth columns included the indicators within the verbal and the visual texts respectively. In the cases of teaching, the verbal transcript included the following headings with one column for each: time, the speaker, the talk (words) and description of what has been done such as writing or drawing on the board (or gestures that is not included in our analysis here).

The analysis was conducted on the Arabic text and later the transcript was translated into English for the purpose of communication with an English speaking audience. In each case, the unit of analysis is the utterance as it appears in textbooks or is made by teachers and students in their interactions during a lesson. In the following, we present each case, examining the ways in which mathematical activity and student activity are construed 
through multimodal communication. We then discuss those cases together before we conclude the article.

\section{Case 1: Textbooks}

The case we have chosen to focus on in this article, as an example of the manifestation of the written mathematics provided for students, is a geometry unit from the Palestinian textbook for Grade 7. An extract from this unit (translated from Arabic) dealing with the topic of congruence, is shown in Figure 1, though the analysis presented here refers to the unit as a whole. This unit was part of the data set used in the project described by Alshwaikh \& Morgan (2013).

\subsection{Nature of mathematics and mathematical activity}

Our framework identifies a number of properties that contribute to the image of mathematics and mathematical activity. As mentioned earlier, we focus only on the issues arising from analysis of the specialisation of the two texts. The Palestinian text has a high density of specialised mathematical words (congruence, segments). Mathematical symbols ( $\overline{A B}$, $\Varangle \mathrm{ABC})$ are used both within the verbal parts of the text and in independent symbolic statements. The diagrams consist of representations of named mathematical objects such as triangles and segments. These objects are identified conventionally by letters labelling vertices and their properties are communicated by conventional marks on the sides and angles. Most of the diagrams are conceptual (Alshwaikh, 2011), displaying the properties of objects and relationships between them rather than representing a process; the dominance of conceptual visual elements is a common characteristic of specialised scientific and mathematical text (Kress \& Van Leeuwen 2006). In summary, the text maintains the mainstream conception about mathematics as impersonal and dealing with a specialised domain that is separate from everyday experience (Davis \& Hersh, 1981; Morgan, 1996).

\subsection{Learner activity}

In order to address the issue of learner activity, we distinguish between engagement in material processes (e.g. measure, calculate) that construe a role as a 'scribbler' and in mental processes (e.g. consider, prove), construing a 'thinker'. According to Rotman (1988), doing mathematics involves undertaking both of these roles: performing operations and reflecting on them. However, the linguistic manifestation of these roles separates them, temporarily positioning the addressee (whether a school student or the reader of an academic paper) in relation to mathematical activity as someone who undertakes a procedure defined by the author or who is invited to share in a creative intellectual process. The Palestinian text engages learners (using an inclusive we or you) in mental processes (e.g. define, notice) as well as in material processes (e.g. find) that construe learners as 'scribblers'. In the section shown in Figure 1, these roles are combined in a single statement (if you noticed the adjacent figure you will find), reflecting their simultaneity in the activity of mathematicians. There is thus expectation that learners will be 'thinkers' (e.g. show, prove, notice, consider), engaged in observation, reflection and reasoning as well as operating on mathematical objects. In the visual component of the text, figures are labelled with specific measurements or marks indicating equality. Learners are thus construed as observing and reasoning about the properties of the shapes. In other parts of the unit, the learners' activity is elicited not only through imperatives but also through use of questions allowing choice in the mode of response, (e.g. If you try to measure $A B$ and $R P$, what do you notice?). In summary, the Palestinian learners appear to be expected to engage in both the scribbler and thinker 
activities that make up the work of a mathematician. They are construed as attending to specific mathematical properties of shapes and reasoning about these and are allowed some degree of choice in deciding how to undertake these roles.

In conclusion, the textbook uses a specialized discourse, emphasising formally defined objects and reasoning about properties. Palestinian learners are expected to engage in material activity; however, the Palestinian text also construes the learner as a 'thinker'. The combination of scribbler and thinker activity suggests that the Palestinian text as a whole seeks to apprentice learners into specialised mathematical discourse (cf. Dowling, 1998). 


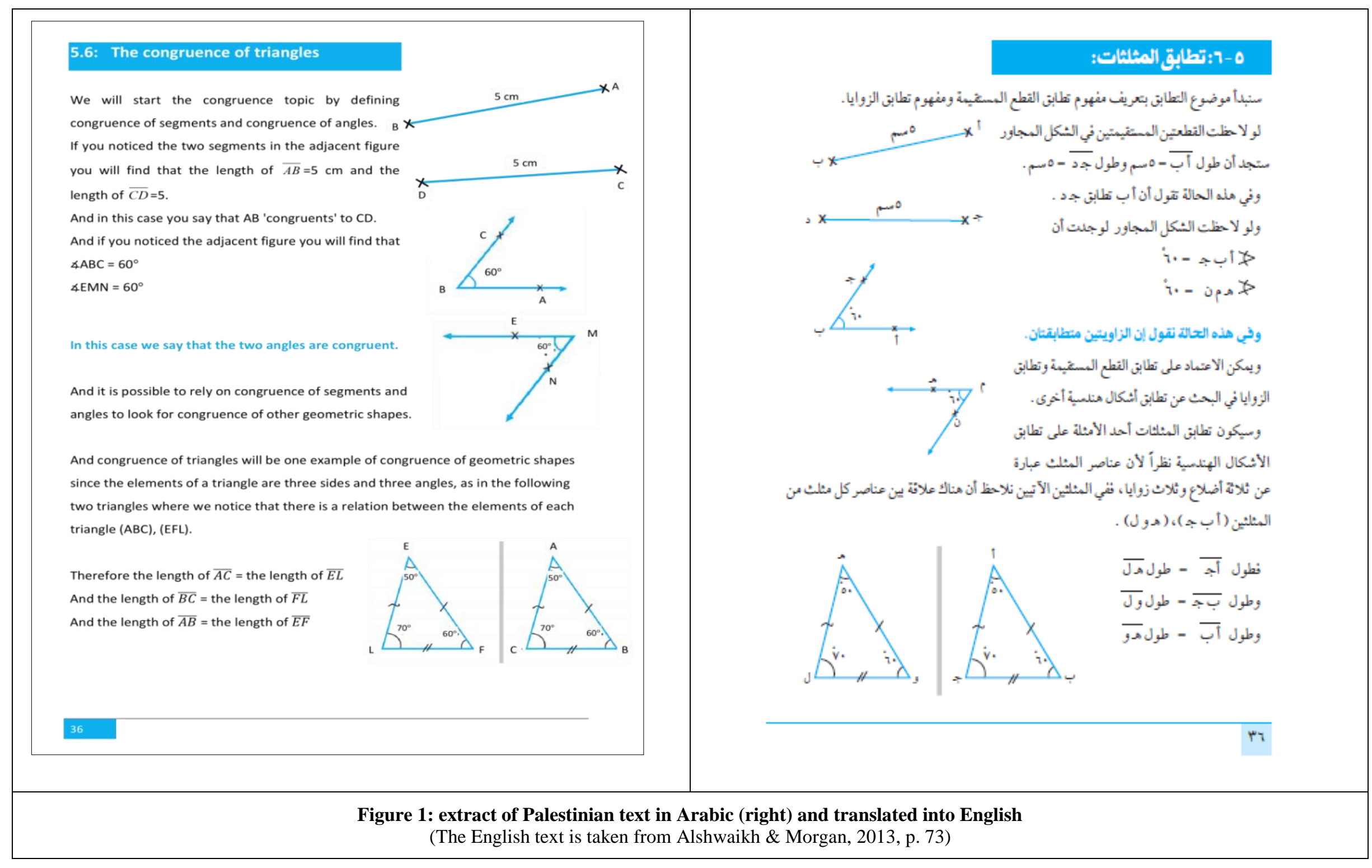




\section{Case 2: Teacher $M$}

Teacher $\mathrm{M}$ has a first degree in physics and has been in teaching for six years. Her main responsibility involves teaching mathematics in English in grades 10-12 as this private school offers such courses for learners preparing for international qualifications as an alternative to the Palestinian high school diploma. In the observed lesson, however, she was teaching "Multiplying mixed numbers" in Arabic to a grade 6 class (11-12 years old). In the following, we present the way in which mathematics and roles of learners were represented by using the analytic framework.

\subsection{Nature of mathematics and mathematical activities}

As in analysing the textbook, we focus only on the issues arising from analysis of the specialisation issue in classrooms. Teacher $\mathrm{M}$ used many mathematical specialised words in her lesson such as proper and improper fraction, mixed number, long division, distributive property. In addition, we noticed Teacher $\mathrm{M}$ introduced her students into the discourse of mathematics through her communication of rules and procedures. The rules communicated referred to conventions of doing mathematics as Teacher $M$ conceived these. She also provided her students with specific procedures to solve problems mathematically.

The importance of rules or conventions as a specialised component of mathematics was identified through general statements that Teacher $\mathrm{M}$ made about mathematics explicitly (using the word mathematics, e.g. in mathematics, it is necessary to write the question then the solution) and through the use of always, or through the use of 'timeless-type' statements (using the present tense to indicate generality), for example after she asked one student to multiply $\frac{7}{2} \times \frac{17}{2}$, she examined the whole class: "how do we multiply fractions?" [asking for a formula or a procedure (see below): $\left.\frac{\text { numerator } \times \text { numerator }}{\text { denominator } \times \text { denominator }}\right]$.

Other conventions she communicated related to the skills or strategies required to do mathematics, especially mental calculations. She used the word "mentally" seven times, in cases such as the following:

- 16 divided by 3? Mentally, quickly.

- Who can multiply [ $17 \times 7]$ mentally without writing anything on the board?

- It is not OK to re-write the 17 times 7 and use a lot of time. I have to make my mind work and do it mentally.

While counting the occurrences of the use of the word mentally is helpful and in this case gives a good sense of the overall message, a quantitative analysis is not necessarily conclusive. Instead, looking at patterns of occurrence (Newman, 2016) could be an alternative strategy to analyse the dominant discourse. For example, the notion of drill and practice was suggested by Teacher $\mathrm{M}$ in her comments: "Grade 6: we have to practice. Every weekend put problems on long division and multiplication and practice. We have to do a lot of practice "in order to become fast in it [mathematics]". This notion of practice was repeatedly associated with doing multiplications mentally in order to save time and make learners fast in solving mathematical problems (which is a common belief about what makes people good at mathematics, e.g. Davis \& Hersh, 1981).

However, becoming fast should not come at the expense of the way in which mathematics is communicated, such as writing in a neat and organised way. Teacher $\mathrm{M}$ also made generalities about mathematics and the way in which it has to be written or presented: writing 
("in mathematics, it is necessary to write the questions and then the solution"; "in mathematics, we like not keep writing equal equal [equal sign] but start new line for the new procedure") or the organisation of writing (organisation is the most important thing in mathematics; You should make your solution's steps clear and understandable; whenever your method is clear, your answer will be correct).

The procedural nature of mathematics was identified through the inclusion of circumstances suggesting order or steps in doing mathematics, for example, using the term before. Whenever Teacher $M$ asked her students to multiply two mixed fractions she told them that they need to check the type of the fraction and convert it to an improper fraction before operating the multiplication. Later, she added another procedure for students to follow before multiplying the two fractions: Cancel if there is cancellations [simplify by taking out the common factors]. The reason for that, she justified,

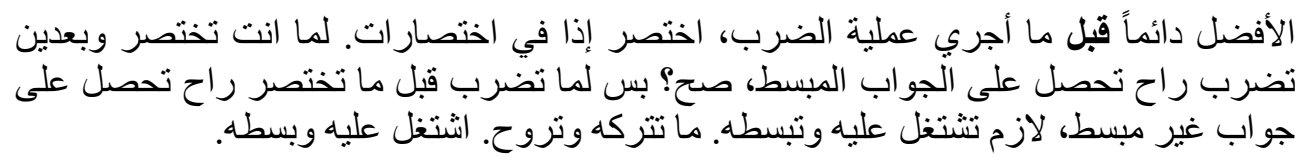

It is always better to do the cancellations before doing the multiplication. When you cancel and then multiply, you will get the simplest [form of] answer, right? But if you multiply before cancelling you will get an answer that is not simplified, you have to work on it and simplify it. Don't leave it and go. Work on it and simplify it.

To conclude, the way in which mathematical activities are represented in Teacher M's explanatory communication and teaching is consistent with the common view of doing mathematics that it should follow procedures and be done mentally, fast, organised and neat (Davis \& Hersh, 1981).

\subsection{Learner activity}

Again, as we analysed the roles of learners presented in the textbooks and how they are positioned as scribblers and/or thinkers, we looked at the kind of activities that students engaged in and the possibilities offered for them to make decisions. First, most of the processes that Teacher $\mathrm{M}$ offered her students were of a material kind (e.g. convert, cancel) but there were some cases where the processes was presented as mental (e.g. the use of the word 'mentally' when instructing the students to execute multiplication and the division). As well as giving students instructions, Teacher $\mathrm{M}$ demanded activities from students by asking questions. Teacher $\mathrm{M}$ posed questions to almost every student, engaging them in the lesson. Most of these questions were, however, closed questions, again involving material processes, such as before I multiply the mixed number, what should I do with it?, or cancel what?

Numerator with? In addition, she presented many prompts and cues for students to help them to answer her questions. Often these were of a "fill in the blank" format, rather than allowing students to make mistakes or use trial and improvement. In the discourse of Teacher M's classroom, learners are predominantly construed as scribblers. Although they are urged to calculate mentally, this refers only to the mode of calculation and the thinker role (show, prove, notice, consider) found in the textbook is largely absent. There is, however, an additional expectation that students should communicate their activity to the teacher; instructions involving communication were frequent, including remind $u \mathrm{~s}$, write, and show $m e$. These instructions motivate the scribbling role of learners and at the same time they reflect the regulative discourse of the classroom (Bernstein, 1990), expecting learners not 
only to engage in mathematical activity but also to display it to the teacher (and possibly to classmates) for evaluation.

In conclusion, Teacher $\mathrm{M}$ used specialised terms in mathematics and insisted that her students should follow mathematical procedures and conventions. The use of words such as numerator (بسط), denominator (كقام), fraction (كسر), improper fraction (عدد كسري), etc. was dominant and consistent in this lesson. Specialised terms for the processes of calculations, especially multiply, divide, and cancel were also dominant. The specialisation phenomenon was manifested further through the distinction between procedures specific to the calculations being taught and more general expectations about how to behave mathematically. Teacher $\mathrm{M}$ focused on conventions to be used while doing mathematics. Many times during the lesson, Teacher M would also tell her students how to do mathematics 'properly', including, for example, the need to practice over the weekend and to solve many problems, to do calculations mentally, or to pay attention to the organisation of their final answer.

\section{Case 3: Teacher $H$}

Teacher $\mathrm{H}$, who teaches grade 5, has a master's degree in (science) education with a first degree in physics. She has been teaching mathematics for three years. There were 21 students in her grade 5 class and they were learning about reading and writing billions. In the following, we again use the analytic framework to discuss how mathematics and the role of learners were represented in this classroom.

\subsection{Nature of mathematics and mathematical activities}

In contrast to Teacher M's procedural approach, Teacher $\mathrm{H}$ was trying to show her students the logic of the system behind the process of extending the place value system to include and name large numbers. In doing this, she was focusing on structure and conceptual understanding. However, her use of specialised vocabularies was limited to place value (القيمة (المنزلية) and labels such as ones (آحاد) and thousands (آلاف). An interesting phenomenon, also contrasting with Teacher M's practice, was that she brought something from students' everyday life and used it as a metaphor to make learning numbers more accessible for them. Teacher $\mathrm{H}$ used a 'building' metaphor to express the expansion of the place value notation structure (ones, thousands, millions) and to introduce new place values. For example, in introducing thousands she commented:

- We were introduced to more numbers, right? We entered to a slightly larger numbers or families. We went up in our building; we were in the ground floor, right? Then we went up to the first floor. Similarly, we found the same design of the first or the ground floor, but it has a different name. What did we call it Samer?

- Thousands [answered the student Samer].

- Excellent. We entered to a new family that is higher from the ones and we called it, what? Thousands. Notice that it has the same design as the ones ... ones, tenths, hundreds. Again, we have the same thing, the same apartments that called ten thousand and hundred thousand.

While the shortcomings of the building metaphor are not relevant to the focus of this article, it is worth mentioning that the form of this metaphor does not match the other forms of representing numbers and place value used in the lesson. For example, there are different representations of the number 9,432,643,610 that the teacher discussed such as expanded 
form or using the place value chart. Using the building metaphor makes the representation of that number (vertical as building) difficult to read and write.

\subsection{Learner activity}

The material processes presented in this lesson were dominant through asking for examples (e.g. give me example), reading and writing numbers, naming and arranging numbers. Students were primarily scribblers, mainly answering teacher's questions with expected or 'required' answers. Teacher $\mathrm{H}$, as Teacher $\mathrm{M}$, asked many closed questions such as what did we call it? To what family does it belong to? On one occasion, Teacher $\mathrm{H}$ did raise an openended question about the reason to learn about such big numbers, encouraging students to give answers and imputing a thinker role for them. They were also asked to "notice" patterns brought to their attention by the teacher.

In conclusion, as in the case of Teacher M, the role of learners in Teacher H's class was predominantly, though not exclusively, as scribblers. However, the discourse was considerably less specialised in this classroom. Not only was the range of specialised vocabulary very limited but the language of the everyday context of families living in buildings was extensively employed.

\section{Discussion}

Our aim was to draw a picture of the way mathematics is construed in the Palestinian schools by analysing texts from the practice of teaching and learning mathematics. Two questions were posed: What is mathematics and what kinds of activity are construed as mathematical in school mathematics? and What kinds of mathematical activity are students expected to engage with? We approached these questions by analysing examples of texts arising within the discourse of school mathematics in Palestine, considering the verbal language, notations and diagrams used in a textbook and the verbal language of teaching interactions in two lessons.

The discourse of mathematics as presented in the three discussed cases used specialised mathematical terms. In the analysis of the textbook, we found a highly specialized discourse, emphasising formally defined objects and reasoning about properties. Both teachers also used specialised names for mathematical objects, though in Teacher H's case this vocabulary was less extensive and less frequent and was augmented by the everyday language of the building metaphor.

Most of the mathematical activities presented in both written and spoken communication were of material nature. The specialised vocabulary was largely used in Teacher M's case in which mathematics was construed as a subject focusing mainly on carrying out procedures and calculation processes that students need to acquire and apply as quickly as possible, using mental arithmetic. This practice is not surprising since it reflects a common and dominant view of mathematics (Davis \& Hersh, 1981). In contrast, however, Teacher H focused on the structure and the conceptual understanding of place value through using colloquial rather than specialised language. Of course, the specific topics being taught may have influenced the extent of the focus on procedures or on structure and concepts.

All three cases tended to present a picture of the learners of mathematics as scribblers, engaging in material processes and communicating the results. The textbook, however, also construes the learner as a 'thinker'. The combination of scribbler and thinker activity suggests that the textbook as a whole seeks to apprentice learners into specialised mathematical discourse (cf. Dowling, 1998). However, while Palestinian textbooks appear to 
construe learners as engaged in reasoning, the practice of teaching and learning of mathematics in Palestinian the classrooms studied reflects a different reality. The analysis of the spoken language in teaching revealed that role of the learners is a predominantly scribbler role or, as we described it here, "fill in the blank" role with few opportunities to engage in reasoning (a role frequently remarked upon in studies of classrooms elsewhere). Students are thus expected to act as scribblers and to answer what the teacher hints for. This result is compatible with the observation of the central role of textbooks in the Palestinian context $\mathrm{t}^{\mathrm{iii}}$ where students are expected to follow what the authors of the textbooks have done or simply to repeat the activity already illustrated in the examples (Alshwaikh, 2016).

In section 2 above, we identified Arabic diglossia as an issue that needs investigation in the context of mathematics education in Palestine. While the present study cannot make a major contribution to this issue, our analysis identifies complexity in the relationship between diglossia (shifting between use of Standard and Colloquial Arabic) and the use of specialised mathematical or everyday language. It is relevant to consider here the use of metaphor in Teacher H's lesson, its linguistic characteristics and its link to Palestinian social and cultural practice. Teacher H used the 'building' metaphor for the place value system. Her choice of this metaphor may have been suggested by the (specialised mathematical) Arabic word for the place or digit, that is manzilah (منزلة), which is etymologically derived from the word manzil (منزل) meaning home or house (also other meanings such as 'the place to stay' and 'status'). It is interesting to think of the way in which this word (manzilah) moves between the different forms of Classic/Colloquial Arabic and of specialised/everyday mathematics. manzilah is a classic (fus-ha) word that may appear in a school mathematics textbook mainly with the meaning of a place value in the number system. In order to explain this notion of place value, Teacher $\mathrm{H}$ takes another meaning, house, and uses it to describe the whole structure of the place value system based on her view, creating a metaphor such as 'the structure of place value is as a building with different floors' bringing a word (building) from the everyday life of the students. The phenomenon of a word having slightly different, though related, meanings in specialised and everyday language is also common to English (Pimm, 1987) but the shift between Classic and Colloquial Arabic vocabulary introduces further complexity. One of the questions one may face might be: does the word manzilah thus become part of colloquial/everyday language? Or are grammatical structures along with vocabulary operating in the effect of the different forms of language on the production of mathematical activity? The issue of boundaries and relationships between the different forms of Arabic language and mathematics discourse need further investigation.

Finally, we reflect on the analytic framework. This framework was developed to analyse the kind of activities involved in school mathematics and the expected role of school students in the multimodal written discourse of textbooks. In this article, we have also used it to analyse those activities in the spoken language in two classrooms. We consider this to be an important contribution to the development of tools for studying school mathematics, providing a unified analytical framework that can be applied to a wide range of texts produced and consumed within mathematics classrooms. However, an issue arose in analysing the classroom spoken language concerning the use of conventions in doing mathematics versus the use of the conventional expression as suggested by the framework in analysing the specialisation issue. For example, we observed in the case of Teacher $M$ that she insisted on introducing her students to the conventions of doing mathematics (from her point of view): calculating mentally, presenting solutions in a particular format, etc. We consider this form of reference to conventions to also be an indicator of the specialisation of the discourse - though in this case a specifically school mathematics discourse. Most research on the use of specialised language in mathematics education has focused exclusively 
on those aspects of mathematical language that form part of an academic mathematics register; the specialised activities of school mathematics classrooms have had less attention. It may be that Bernstein's (1990) distinction between regulative and instructional discourse could inform the development of the framework here, as in Adler's (Adler \& Ronda, 2015) mathematics discourse analysis or Christie's (2002) analysis of classroom discourse. Insisting, for example, that calculations should be performed mentally contributes to the formation of particular kinds of learners, their attributes, dispositions and behaviours as 'good students' of mathematics, rather than contributing to their acquisition of mathematical knowledge. Christie's analytic approach did not distinguish forms of regulative discourse that were distinctive of a particular school discipline; identifying regulative discourse specialised to mathematics could contribute a further dimension to the framework, enriching its potential for analysing how learners of mathematics are formed through classroom discourse.

\section{Acknowledgments}

Thanks to the teachers, students and their school who agreed to video record them. A special thanks to the colleague who did the video recording. Thanks to the Palestinian Curriculum Development Center for its permission to reproduce the text in Figure 1. The project "Analysing Palestinian school mathematics textbooks" was supported by the British Academy International Partnership and Mobility Scheme.

\section{References}

Adler, J. \& Ronda, E. (2015). A Framework for Describing Mathematics Discourse in Instruction and Interpreting Differences in Teaching. African Journal of Research in Mathematics, Science and Technology Education, 19(3), 237-254. DOI: 10.1080/10288457.2015.1089677

Alomar, F. (2015). Beliefs of upper Basic level mathematics teachers in the Governate of Ramallah and Al-Bireh about the nature of mathematics (Unpublished master's thesis). Birzeit University, Birzeit, Palestine.

Al-Ramahi, R., Alshwaikh, J., \& Masad, F. (2016). Learning geometry in Palestine: An outlook at students and teachers. Mediterranean Journal for Research in Mathematics Education, 15, 77-94.

Alshwaikh, J. (2011). Geometrical diagrams as representation and communication: A functional analytic framework (Unpublished $\mathrm{PhD}$ thesis). Institute of Education, University of London, London, UK.

Alshwaikh, J. (2016). Investigating the geometry curriculum in Palestinian textbooks: Towards multimodal analysis of Arabic mathematics discourse. Research in Mathematics Education, 18(2), 165-181. DOI: 10.1080/14794802.2016.1177580

Alshwaikh, J., \& Morgan, C. (2013). Analysing the Palestinian school mathematics textbooks: A multimodal (multisemiotic) perspective. Proceedings of the British Society for Research into Learning Mathematics, 33(2), 70-75.

Baker, D. (1998). Numeracy as Social Practice. Literacy and Numeracy Studies, 8(1), 37-51.

Bernstein, B. (1990). Class, Codes and Control, Vol.IV: The Structuring of Pedagogic Discourse. London: Routledge.

Christie, F. (2002). Classroom Discourse Analysis. London: Continuum.

Davis, P. J., \& Hersh, R. (1981). The mathematical experience. London: Penguin Books. 
Dowling, P. (1998). The sociology of mathematics education: Mathematical myths/ pedagogic texts. London: Falmer.

Duval. R. (2006). A cognitive analysis of problems of comprehension in a learning of mathematics. Educational Studies in Mathematics, 61(1-2), 103-131.

Halliday, M. A. K. (1985). An introduction to functional grammar. London: Edward Arnold.

Hashem-Aramouni, E. (2011). The Impact of Diglossia on Arabic Language Instruction in Higher Education: Attitudes and Experiences of Students and Instructors in the U.S. (Unpublished PhD dissertation). California State University, Sacramento, USA.

Jewitt, C., Bezemer, J., \& O'Halloran, K. (2016). Introducing Multimodality. London: Routledge.

Kress, G. (2011). Multimodal discourse analysis. In J. P. Gee \& M. Handford (Eds.), The Routledge Handbook of Discourse Analysis (35-50). London: Routledge.

Kress, G., \& Van Leeuwen, T. (2006). Reading images: The grammar of visual design (2nd ed.). London: Routledge.

Lerman, S. (2000). The social turn in mathematics education research. In J. Boaler (Ed.), Multiple perspectives on mathematics teaching and learning (pp. 19-44). Westport: Ablex.

Maamouri, M. (1998). Language education and human development: Arabic diglossia and its impact on the quality of education in the Arab region. Paper presented at the The World Bank, The Mediterranean Development Forum, Marrakech, 3-6 September 1998.

Maheux, J. F. \& Proulx, J. (2015). Doing|mathematics: Analysing data with/in an enactivistinspired approach. ZDM Mathematics Education, 47(2), 211-221. https://doi.org/10.1007/s11858-014-0642-7

Ministry of Education - MoE. (2016). Preliminary results of the National Assessment Study "Attainment of the fourth and the tenth graders in Arabic language, mathematics and science 2015/2016”. Ramallah: MoE.

Morgan, C. (1996). Writing mathematically: The discourse of investigation. London: Falmer Press.

Morgan, C. (2006). What does social semiotics have to offer mathematics education research? Educational Studies in Mathematics, 61(1/2), 219-245. doi:10.1007/s10649006-5477-x

Morgan, C., Mariotti, M. A., \& Maffei, L. (2009). Representation in computational environments: epistemological and social distance. International Journal of Computers for Mathematical Learning, 14, 241-263.

Morgan, C. \& Sfard, A. (2016). Investigating changes in high-stakes mathematics examinations: A discursive approach. Research in Mathematics Education, 18(2), 92119, DOI: $10.1080 / 14794802.2016 .1176596$

Mullis, I.V. S., Martin, M.O., Foy, P., \& Arora, A. (2012). TIMSS 2011 International Results in Mathematics. Chestnut Hill, MA: TIMSS and PIRLS International Study Centre, Boston College.

O'Halloran, K. L. (2005). Mathematical discourse. London: Continuum.

Pimm, D. (1987). Speaking Mathematically: Communication in mathematics classrooms. London: Routledge. 
Rewadi, F. (2005). A comparison of mathematical reasoning in the Palestinian curriculum with the National Council of Teachers of Mathematics Standards 2000. (Masters dissertation), Birzeit University, Palestine.

Rotman, B. (1988). Towards a semiotics of mathematics. Semiotica, 72(1/2), 1-35.

Sfard, A. (2008). Thinking as communicating: Human development, the growth of discourses, and mathematizing. Cambridge, UK: Cambridge University Press.

Sfard, A. (2012). Why mathematics? What mathematics? The Mathematics Educator, 22(1), $3-16$.

Sinclair, J. \& Coulthard, M. (1975). Towards an analysis of discourse: The English used by teachers and pupils. London: Oxford University Press.

Tang, S., Morgan, C., \& Sfard, A. (2012). Investigating the evolution of school mathematics through the lens of examinations: Developing an analytical framework. Paper presented at the 12th International Congress on Mathematical Education, Topic Study Group 28 on Language and Mathematics, Seoul, Korea.

\footnotetext{
i There are, however, some private schools that follow international curricula, such as International Baccalaureate - IB, IGCSE and SAT, with different textbooks.

ii Kress \& Van Leeuwen (2006) and Alshwaikh (2011) distinguish between narrative and conceptual images (diagrams) in which narrative images tell (by showing) a story while conceptual images show atemporal object or relationships - no actions. Furthermore, conceptual images are more typical of scientific texts.

iii This raises an interesting further question. If the textbook does suggest a thinker role but the way it is used in the classroom emphasises the student as scribbler/ rule follower there is a contradiction. Further need to investigate use of textbooks in the classroom - how to teachers mediate the parts of the textbook that involve thinking?
} 